\title{
The $\mathbf{C} 1 s$ and $\mathbf{N} 1 s$ near edge x-ray absorption fine structure spectra of five azabenzenes in the gas phase
}

Cite as: J. Chem. Phys. 128, 044316 (2008); https://doi.org/10.1063/1.2822985

Submitted: 29 June 2007 . Accepted: 15 November 2007 . Published Online: 31 January 2008

G. Vall-Ilosera, B. Gao, A. Kivimäki, M. Coreno, J. Álvarez Ruiz, M. de Simone, H. Ågren, and E. Rachlew

\section{ARTICLES YOU MAY BE INTERESTED IN}

Detailed study of pyridine at the C1s and N1s ionization thresholds: The influence of the vibrational fine structure

The Journal of Chemical Physics 115, 6426 (2001); https://doi.org/10.1063/1.1397797

Resonances in the K shell excitation spectra of benzene and pyridine: Gas phase, solid, and chemisorbed states

The Journal of Chemical Physics 83, 6099 (1985); https://doi.org/10.1063/1.449601

Pyrimidine and halogenated pyrimidines near edge $\mathrm{x}$-ray absorption fine structure spectra at $\mathrm{C}$ and $\mathrm{N}$ K-edges: experiment and theory

The Journal of Chemical Physics 133, 034302 (2010); https://doi.org/10.1063/1.3442489
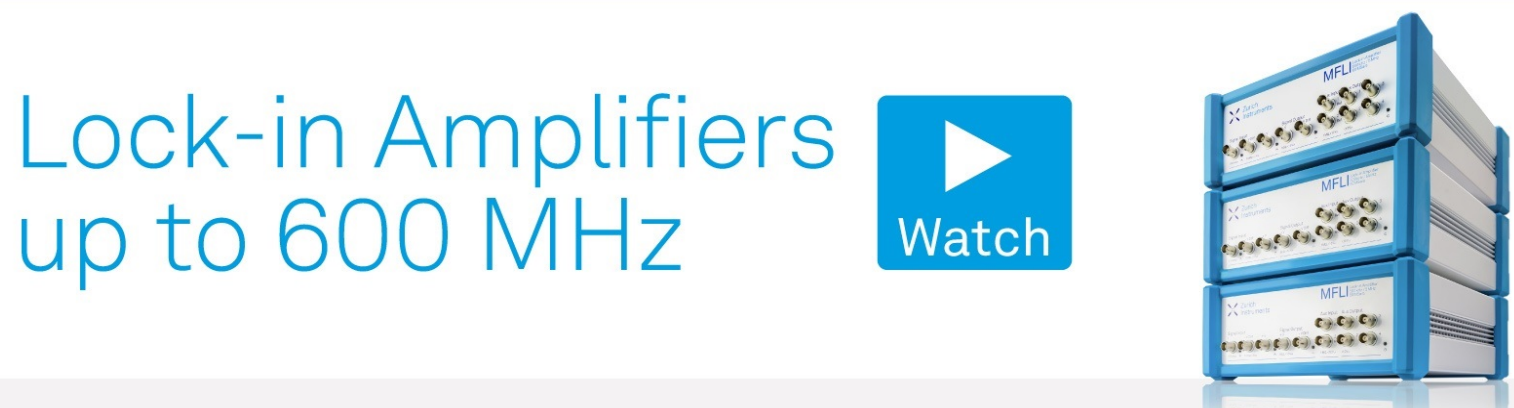

J. Chem. Phys. 128, 044316 (2008); https://doi.org/10.1063/1.2822985

128,044316

(c) 2008 American Institute of Physics. 


\title{
The $\mathrm{C} 1 \mathrm{~s}$ and $\mathrm{N} 1 \mathrm{~s}$ near edge x-ray absorption fine structure spectra of five azabenzenes in the gas phase
}

\author{
G. Vall-llosera ${ }^{a)}$ \\ Department of Physics, School of Engineering Science, Royal Institute of Technology, SE-10691 Stockholm, \\ Sweden \\ B. Gao \\ Department of Theoretical Chemistry, School of Biotechnology, Royal Institute of Technology, SE-10691 \\ Stockholm, Sweden
}

A. Kivimäki
CNR-INFM, Laboratorio Nazionale TASC, 34012 Trieste, Italy

M. Coreno

CNR-IMIP, Montelibretti, 00016 Rome, Italy

J. Álvarez Ruiz

Departamento de Química Láser, Instituto de Químíca-Física Rocasolano Consejo Superior de Investigaciones Científicas, Serrano 119, 28006 Madrid, Spain

M. de Simone

CNR-INFM, Laboratorio Nazionale TASC, 34012 Trieste, Italy

\author{
H. Ågren \\ Department of Theoretical Chemistry, School of Biotechnology, Royal Institute of Technology, SE-10691 \\ Stockholm, Sweden \\ E. Rachlew \\ Department of Physics, School of Engineering Science, Royal Institute of Technology, SE-10691 Stockholm, \\ Sweden
}

(Received 29 June 2007; accepted 15 November 2007; published online 31 January 2008; publisher error corrected 4 February 2008)

Near edge $\mathrm{x}$-ray absorption fine structure spectra have been measured and interpreted by means of density functional theory for five different azabenzenes (pyridine, pyridazine, pyrimidine, pyrazine, and $s$-triazine) in the gas phase. The experimental and theoretical spectra at the $\mathrm{N} 1 s$ and $\mathrm{C} 1 s$ edges show a strong resonance assigned to the transition of the $1 s$ electron in the respective $\mathrm{N}$ or $\mathrm{C}$ atoms to the lowest unoccupied molecular orbital with $\pi^{*}$ symmetry. As opposed to the $\mathrm{N} 1 s$ edge, at the C $1 s$ edge this resonance is split due to the different environments of the core hole atom in the molecule. The shift in atomic core-level energy due to a specific chemical environment is explained with the higher electronegativity of the $\mathrm{N}$ atom compared to the $\mathrm{C}$ atom. The remaining resonances below the ionization potential (IP) are associated to $\sigma$ or $\pi$ orbitals with mixed valence/Rydberg character. Upon $\mathrm{N}$ addition, a reduction of intensity is observed in the Rydberg region at both edges as compared to the intensity in the continuum. Above the IP one or more resonances are seen and ascribed here to transitions to $\sigma^{*}$ orbitals. Calculating the experimental and theoretical $\Delta_{\pi}$ term values at both edges, we observe that they are almost the same within $\pm 1 \mathrm{eV}$ as expected for isoelectronic bonded pairs. The term values of the $\pi^{*}$ and $\sigma^{*}$ resonances are discussed in terms of the total $\mathrm{Z}$ number of the atoms participating in the bond. (C) 2008 American Institute of Physics. [DOI: $10.1063 / 1.2822985]$

\section{INTRODUCTION}

Near edge x-ray absorption fine structure spectroscopy (NEXAFS) has proven to be a sensitive technique for accurate determination of electronic structure of matter. ${ }^{1}$ The technique is atom specific and sensitive to the chemical environment of atoms in molecules, thus providing useful information about local bonding structure and the presence of

\footnotetext{
${ }^{a)}$ Author to whom correspondence should be addressed. Electronic mail: gvall.1losera@gmail.com.
}

specific bonds in molecules. This site dependent technique is now commonly realized by energy selective excitation obtained from synchrotron radiation (SR) available from thirdgeneration synchrotron radiation facilities.

The azabenzene family comprises low- $\mathrm{Z}$ aromatic molecules structurally related and isoelectronic to benzene wherein one or more $\mathrm{CH}$ groups in the six-membered ring is replaced by a nitrogen atom. In this manner, pyridine is the simplest one with one $\mathrm{N}$ atom substituted, followed by pyridazine, pyrimidine, and pyrazine with $2 \mathrm{~N}$ atoms substituted 
in the 1,2,1,3, and 1,4 positions and $s$-triazine which has $3 \mathrm{~N}$ atoms substituted in the 1,3,5 positions. Pyridine, $s$-triazine, and pyridazine are starting materials in the synthesis of compounds used as intermediates in making insecticides and herbicides. Pyridazine, pyridine, and pyrazine are also found within the structure of several pharmaceutical drugs. Pyrimidine is the precursor of the cytosine, thymine, and uracil in DNA and RNA bases. Hence, their spectroscopic properties are the base for the understanding of larger systems in which they are embedded.

In the context of NEXAFS spectroscopy the $K$-shell spectra of these molecules show prominent, structuresensitive resonances around the $K$-edge which serve as a prototype for explaining the spectra of larger molecules as in Ref. 2 and building blocks in polymers. So far most of the studies of these molecules have been performed in the condensed phase. Along this line, we find a study by Plashkevych et al. ${ }^{3}$ where they calculated the NEXAFS spectra for different carbon-nitrogen molecules, clusters, and solids. The molecular and cluster spectra were calculated with the $a b$ initio technique, while the solid state calculations were performed with the density functional full potential augmented plane wave method. Also in the condensed phase, experimental studies of pyridine, pyrazine, and $s$-triazine have been done by Dudde et $a l .{ }^{4}$ where they used deexcitation electron spectroscopy to obtain the kinetic energy distribution of electrons emitted in the decay of $\mathrm{N} 1 s$ core-to-bound-state excitations. Other studies on multilayers of pyridine and pyrazine were done by Bader et al., ${ }^{5}$ Aminpirooz et al., ${ }^{6}$ and Johnson et $a .^{7}$ In the gas phase, pyridine has been extensively studied with NEXAFS by Kolczewski et al. ${ }^{8}$ who recorded high resolution spectra (65 and $150 \mathrm{meV}$ for the $\mathrm{C} 1 \mathrm{~s}$ and $\mathrm{N} 1 \mathrm{~s}$ edges, respectively) for pyridine and deuterated $d_{5}$-pyridine. In order to interpret the experimental spectra and assign the observed peaks they used $a b$ initio and density functional theory approaches. Electron-energy loss (EEL) spectroscopy has been employed by Horsley et $a l^{9}{ }^{9}$ to study pyridine and benzene. The spectra in the gas phase presented in that work were compared to those for the solids and for monolayers chemisorbed on $\mathrm{Pt}(111)$. They found that the gas phase and solid state spectra are largely the same, however, the monolayer spectra show a strong polarization dependence as a function of the x-ray incidence angle because of the orientation of the molecules upon chemiabsorption. Hannay et al. ${ }^{10}$ measured the EEL spectra of gaseous pyridine and pyridazine and used $a b$ initio configuration interaction calculations to aid the assignments of the spectral features. The results were also compared to the $s$-triazine molecule. The latter has also been studied in the gas phase with inner-shell EEL spectroscopy, see work by Apen et al. ${ }^{11}$ where the different resonances were assigned.

Experimental gas phase NEXAFS studies with synchrotron radiation for four of these molecules are not yet reported in the literature nor has a comparative study in the gas phase of these five azabenzenes been performed as far as our knowledge concerns. Thus, we present here experimental and theoretical photoabsorption spectra of pyridine, pyrimidine, pyrazine, pyridazine, and $s$-triazine and analyze their informational content.

\section{EXPERIMENTAL DETAILS}

The measurements were conducted on the undulatorbased Gas Phase Photoemission beamline at the ELETTRA synchrotron facility, Trieste, Italy. ${ }^{12}$

The experimental setup consisted of two chambers placed one after the other in the photon beam direction. The first chamber functioned as a first stage of differential pumping and allowed us to leak the $\mathrm{N}_{2}$ and the $\mathrm{CO}_{2}$ gases for energy calibration purposes. The second vacuum chamber contained a windowless double ionization cell built to perform absolute photoionization cross section measurements. The sketch of the cell is found in Ref. 13, and it is similar to the design used in Ref. 14. Briefly, when the ionization is produced along the light path in the cell the ions are collected by two equally long electrodes $(l)$. Then, according to the Beer-Lambert law, the absorption cross section is given by

$$
\sigma=\frac{1}{n l} \ln \left(\frac{i_{1}}{i_{2}}\right),
$$

where $i_{1}$ and $i_{2}$ are the ion currents collected by the first and second electrodes and $n$ is the number density of the gas in the interaction volume. If we assume an ideal gas behavior in the calculation of the gas density, then Eq. (1) can be written as

$$
\sigma=\frac{k_{B} T}{P l} \ln \left(\frac{i_{1}}{i_{2}}\right),
$$

where $k_{B}$ is the Boltzmann constant, $T$ the temperature in Kelvins, and $P$ the pressure of the gas.

Photocurrents were measured by two picoammeters. Absorption spectra of the different samples were recorded at pressures ranging from 0.9 to $0.3 \times 10^{-1}$ mbar with a 1 mbar full scale range calibrated baratron. The accuracy of the baratron was $1 \times 10^{-4}$ mbar and the pressure was recorded in real time. The pressure was measured directly outside the interaction region and therefore the measurements presented here are in units of relative cross sections. The samples were purchased from Sigma-Aldrich with a stated purity of $>99 \%$ for pyridine and pyrazine, 99\% for pyrimidine, 98\% for pyridazine, and $97 \%$ for $s$-triazine. Pyridine, pyrimidine, and pyridazine are liquid at room temperature, while pyrazine and $s$-triazine are solid at $295 \mathrm{~K}$. All samples were subjected to several cycles of freeze-pump-thaw in situ to eliminate all traces of contaminants. They were held at $295 \mathrm{~K}$ and controlled by a thermocouple device. The photon energy scale was calibrated using the absorption line $\mathrm{N} 1 s \rightarrow \pi^{*}\left(v^{\prime}=1\right)$ of $\mathrm{N}_{2}$ at $401.10 \mathrm{eV}$ (Ref. 15) and the peak of the centroid for the C $1 s \rightarrow \pi^{*}$ transition of $\mathrm{CO}_{2}$ at $290.7 \mathrm{eV}$ (Ref. 16) which were measured simultaneously with the absorption spectra. The resolution at the $\mathrm{N} 1 s$ edge was approximately $90 \mathrm{meV}$ and the resolution at the $\mathrm{C} 1 s$ edge was approximately $75 \mathrm{meV}$.

The experimental energies of the $\mathrm{C}$ and $\mathrm{N} 1 s$ edges of pyrimidine and pyrazine, as well as X-ray photoelectron spectroscopy (XPS) spectra of both molecules, were determined in an independent experiment using the commercial $150 \mathrm{~mm}$ hemispherical electron-energy analyzer (from 
<smiles>Cc1ccc(C)c(C)n1</smiles><smiles>Cc1nc(C)c(C)c(C)n1</smiles>

Pyrimidine<smiles>Cc1cc(C)c(C)nn1</smiles>

Pyridazine<smiles></smiles>

Pyrazine<smiles>Cc1nc(C)nc(C)n1</smiles>

S-triazine
FIG. 1. Numeration of the atoms in pyridine, pyrazine, pyridazine, pyrimidine, and $s$-triazine.
Vacuum Generator) available at the Gas Phase beamline, ELETTRA. ${ }^{17}$ The $\mathrm{C} 1 s$ and $\mathrm{N} 1 s$ binding energy scales were calibrated by measuring the XPS spectra of the sample molecules together with $\mathrm{CO}_{2}$ and $\mathrm{N}_{2}$ gases. We estimate an overall accuracy of $\pm 0.2 \mathrm{eV}$ for the absolute core binding energies of the sample molecules. ${ }^{18}$

\section{COMPUTATIONAL DETAILS}

The geometries of the five studied molecules: pyridine $\left(C_{2 v}\right)$, pyrimidine $\left(C_{2 v}\right)$, pyridazine $\left(C_{2 v}\right)$, pyrazine $\left(D_{2 h}\right)$, and $s$-triazine $\left(D_{3 h}\right)$ are shown in Fig. 1. They were optimized at the B3LYP/aug-cc-pVDZ level using the GAUSSIAN 03 program. ${ }^{19}$ The optimized bond lengths and angles of these five molecules are given in the Appendix section.

The total spectra at the carbon or nitrogen $1 s$ edges are obtained by computing the NEXAFS spectra for the symmetry-independent carbon or nitrogen atoms and summing up the different contributions scaled with the relative abundance of every type of carbon or nitrogen atom. The NEXAFS spectra of each symmetry-independent carbon or nitrogen atoms were calculated using the DEMON program. ${ }^{20}$ We used the gradient-corrected Becke (BE88) exchange functional $^{21}$ and the Perdew (PD86) correlation functional. ${ }^{22}$ The orbital basis set used for the nonexcited carbon and nitrogen atoms was a triple- $\zeta$ valence and polarizing $d$-function type with the following form $(7111 / 411 / 1)$. Hydrogen atoms were represented by the double- $\zeta$ valence plus polarization scheme $(311 / 1)$. The IGLO-III basis set of Kutzelnigg, Fleischer, and Shindler ${ }^{23}$ was used for the excited carbon or nitrogen atom. In order to help the convergence of the corehole state, an effective core potential was used to describe the other carbon or nitrogen atoms. The theoretical spectra

TABLE I. Theoretical and experimental N $1 s$ ionization potentials and excitation energies for all five molecules. Term values $\Delta_{\pi}$ and $\Delta_{\sigma}$ are shown. All computed energies include the relativistic correction $(+0.3 \mathrm{eV})$. The experimental error is $\pm 0.2 \mathrm{eV}$.

\begin{tabular}{|c|c|c|c|c|c|c|c|c|c|c|}
\hline \multirow[b]{2}{*}{ Peak } & \multicolumn{2}{|c|}{ Pyridine } & \multicolumn{2}{|c|}{ Pyrimidine } & \multicolumn{2}{|c|}{ Pyridazine } & \multicolumn{2}{|c|}{ Pyrazine } & \multicolumn{2}{|c|}{$s$-triazine } \\
\hline & Expt. & $\Delta \mathrm{KS}$ & Expt. & $\Delta \mathrm{KS}$ & Expt. & $\Delta \mathrm{KS}$ & Expt. & $\Delta \mathrm{KS}$ & Expt. & $\Delta \mathrm{KS}$ \\
\hline 1 & 398.8 & $\begin{array}{c}398.38 \\
\pi^{*}\left(b_{1}\right)\end{array}$ & 398.8 & $\begin{array}{l}398.36 \\
\pi^{*}\left(a_{2}\right)\end{array}$ & 399.0 & $\begin{array}{c}398.54 \\
\pi^{*}\left(a_{2}\right)\end{array}$ & 398.8 & $\begin{array}{l}398.23 \\
\pi^{*}\left(b_{3 u}\right)\end{array}$ & 398.9 & $\begin{array}{c}398.36 \\
\pi^{*}\left(e^{\prime \prime}\right)\end{array}$ \\
\hline 2 & & & 399.9 & $\begin{array}{c}399.44 \\
\pi^{*}\left(b_{1}\right)\end{array}$ & 399.6 & $\begin{array}{c}399.95 \\
\pi^{*}\left(b_{1}\right)\end{array}$ & & & 399.9 & \\
\hline 3 & & $\begin{array}{l}401.45 \\
\sigma^{*}\left(a_{1}\right)\end{array}$ & & $\begin{array}{l}401.78 \\
\sigma^{*}\left(a_{1}\right)\end{array}$ & & $\begin{array}{l}402.17 \\
\sigma^{*}\left(a_{1}\right)\end{array}$ & & $\begin{array}{r}402.06 \\
\sigma^{*}\left(a_{g}\right)\end{array}$ & & \\
\hline 4 & 402.6 & $\begin{array}{l}402.32 \\
\pi^{*}\left(b_{2}\right)\end{array}$ & 402.8 & $\begin{array}{c}402.33 \\
\pi^{*}\left(b_{1}\right)\end{array}$ & 402.7 & $\begin{array}{r}402.52 \\
\pi^{*}\left(a_{2}\right)\end{array}$ & 402.8 & $\begin{array}{l}402.36 \\
\pi^{*}\left(b_{2 g}\right)\end{array}$ & 402.9 & $\begin{array}{l}402.34 \\
\pi^{*}\left(a_{2}^{\prime \prime}\right)\end{array}$ \\
\hline 5 & 404.9 & & 404.9 & & 404.7 & & 405.4 & & 405.2 & \\
\hline 6 & 408.1 & & 408.7 & & 408.4 & & 408.0 & & 409.0 & \\
\hline 7 & & & 415.1 & & 415.1 & & 415.2 & & 415.3 & \\
\hline IP & $404.9^{\mathrm{a}}$ & 404.47 & $405.2^{\mathrm{b}}$ & 404.96 & $404.88^{c}$ & 405.44 & $405.6^{\mathrm{b}}$ & 405.20 & $404.9^{\mathrm{d}}$ & 405.50 \\
\hline $\begin{array}{l}\Delta_{\pi} \\
\Delta_{\sigma}\end{array}$ & $\begin{array}{l}-6.1 \\
+3.2\end{array}$ & -6.09 & $\begin{array}{l}-6.4 \\
+3.5\end{array}$ & -6.60 & $\begin{array}{l}-5.9 \\
+3.5\end{array}$ & -6.90 & $\begin{array}{l}-6.8 \\
+2.4\end{array}$ & -6.97 & $\begin{array}{l}-6.0 \\
+4.1\end{array}$ & -7.14 \\
\hline
\end{tabular}

${ }^{\mathrm{d}}$ Reference 11. 
TABLE II. Theoretical and experimental C $1 s$ ionization potentials and excitation energies for all five molecules. Term values $\Delta_{\pi}$ and $\Delta_{\sigma}$ are shown. All computed energies include the relativistic correction $(+0.2 \mathrm{eV})$. The experimental error is estimated to be $\pm 0.2 \mathrm{eV}$.

\begin{tabular}{|c|c|c|c|c|c|c|c|c|c|c|}
\hline \multirow[b]{2}{*}{ Peak } & \multicolumn{2}{|c|}{ Pyridine } & \multicolumn{2}{|c|}{ Pyrimidine } & \multicolumn{2}{|c|}{ Pyridazine } & \multicolumn{2}{|c|}{ Pyrazine } & \multicolumn{2}{|c|}{$s$-triazine } \\
\hline & Expt. & $\Delta \mathrm{KS}$ & Expt. & $\Delta \mathrm{KS}$ & Expt. & $\Delta \mathrm{KS}$ & Expt. & $\Delta \mathrm{KS}$ & Expt. & $\Delta \mathrm{KS}$ \\
\hline $1^{\prime}$ & 284.9 & $\begin{array}{c}284.76 \\
\mathrm{C}_{2}: \pi^{*}\left(b_{1}\right) \\
284.71 \\
\mathrm{C}_{3}: \pi^{*}\left(b_{1}\right)\end{array}$ & 284.9 & $\begin{array}{c}284.72 \\
\mathrm{C}_{3}: \pi^{*}\left(b_{1}\right)\end{array}$ & 285.5 & $\begin{array}{c}284.56 \\
\mathrm{C}_{3}: \pi^{*}\left(a_{2}\right)\end{array}$ & 285.3 & $\begin{array}{l}285.03 \\
\pi^{*}\left(b_{3 u}\right)\end{array}$ & 285.9 & $\begin{array}{r}285.49 \\
\pi^{*}\left(e^{\prime \prime}\right)\end{array}$ \\
\hline $1^{\prime \prime}$ & 285.5 & $\begin{array}{c}285.17 \\
\mathrm{C}_{1}: \pi^{*}\left(b_{1}\right) \\
285.50 \\
\mathrm{C}_{2}: \pi^{*}\left(a_{2}\right)\end{array}$ & 285.4 & $\begin{array}{c}285.08 \\
\mathrm{C}_{2}: \pi^{*}\left(a_{2}\right)\end{array}$ & 286.2 & $\begin{array}{c}285.12 \\
\mathrm{C}_{1}: \pi^{*}\left(a_{2}\right) \\
285.67 \\
\mathrm{C}_{1}: \pi^{*}\left(b_{1}\right) \\
285.79 \\
\mathrm{C}_{3}: \pi^{*}\left(b_{1}\right)\end{array}$ & 285.8 & $\begin{array}{l}285.86 \\
\pi^{*}\left(a_{u}\right)\end{array}$ & & \\
\hline $1^{\prime \prime \prime}$ & 285.8 & $\begin{array}{c}286.11 \\
\mathrm{C}_{1}: \pi^{*}\left(a_{2}\right)\end{array}$ & 285.8 & $\begin{array}{c}285.56 \\
\mathrm{C}_{1}: \pi^{*}\left(b_{1}\right)\end{array}$ & 286.5 & & & & & \\
\hline 2 & 287.3 & $\begin{array}{c}286.89 \\
\mathrm{C}_{2}: \sigma^{*}\left(a_{1}\right) \\
287.09 \\
\mathrm{C}_{3}: \sigma^{*}\left(a_{1}\right)\end{array}$ & 287.3 & $\begin{array}{c}287.12 \\
\mathrm{C}_{3}: \sigma^{*}\left(a_{1}\right)\end{array}$ & 288.2 & $\begin{array}{c}287.33 \\
\mathrm{C}_{3}: \pi^{*}\left(a_{1}\right)\end{array}$ & & & & \\
\hline 3 & 287.9 & $\begin{array}{c}287.69 \\
\mathrm{C}_{1}: \sigma^{*}\left(a_{1}\right) \\
287.66 \\
\mathrm{C}_{2}: \sigma^{*}\left(b_{2}\right)\end{array}$ & 288.3 & $\begin{array}{c}288.15 \\
\mathrm{C}_{2}: \pi^{*}\left(a_{1}\right) \\
288.71 \\
\mathrm{C}_{3}: \pi^{*}\left(b_{2}\right)\end{array}$ & 288.7 & $\begin{array}{c}287.87 \\
\mathrm{C}_{1}: \sigma^{*}\left(a_{1}\right)\end{array}$ & 288.2 & $\begin{array}{l}287.98 \\
\sigma^{*}\left(a_{g}\right)\end{array}$ & 298.8 & $\begin{array}{l}289.36 \\
\sigma^{*}\left(a_{2}^{\prime \prime}\right) \\
290.13 \\
\pi^{*}\left(a_{1}^{\prime}\right)\end{array}$ \\
\hline $4^{\prime}$ & 288.6 & $\begin{array}{c}289.27 \\
\mathrm{C}_{2}: \pi^{*}\left(a_{1}\right)\end{array}$ & 289.3 & $\begin{array}{c}289.14 \\
\mathrm{C}_{1}: \sigma^{*}\left(a_{1}\right) \\
290.17 \\
\mathrm{C}_{1}: \pi^{*}\left(b_{1}\right) \\
288.87 \\
\mathrm{C}_{2}: \sigma^{*}\left(b_{1}\right) \\
289.33 \\
\mathrm{C}_{2}: \pi^{*}\left(b_{2}\right)\end{array}$ & 289.1 & $\begin{array}{c}289.55 \\
\mathrm{C}_{1}: \pi^{*}\left(a_{2}\right) \\
288.61 \\
\mathrm{C}_{3}: \pi^{*}\left(a_{2}\right)\end{array}$ & 289.1 & $\begin{array}{l}288.74 \\
\sigma^{*}\left(b_{2 g}\right) \\
288.94 \\
\pi^{*}\left(b_{2 u}\right)\end{array}$ & 290.5 & $\begin{array}{l}290.40 \\
\sigma^{*}\left(e^{\prime}\right)\end{array}$ \\
\hline $4^{\prime \prime}$ & 289.2 & $\begin{array}{c}289.99 \\
\mathrm{C}_{1}: \pi^{*}\left(a_{1}\right) \\
289.44 \\
\mathrm{C}_{3}: \pi^{*}\left(a_{1}\right)\end{array}$ & 289.6 & $\begin{array}{c}290.96 \\
\mathrm{C}_{1}: \pi^{*}\left(a_{1}\right)\end{array}$ & & & & & & \\
\hline 5 & 290.5 & & 290.2 & & 289.9 & & & & 291.9 & \\
\hline 6 & 294.4 & & 295.5 & & 296.0 & & 295.4 & & 296.1 & \\
\hline 7 & 301.6 & & 302.6 & & 301.4 & & 302.4 & & 303.2 & \\
\hline IP & $290.6^{\mathrm{a}}$ & $\begin{array}{l}C_{1}: 291.05 \\
C_{2}: 290.48 \\
C_{3}: 290.75\end{array}$ & $\begin{array}{l}\mathrm{C}_{1}: 292.4^{\mathrm{b}} \\
\mathrm{C}_{2}: 292.0^{\mathrm{b}} \\
\mathrm{C}_{3}: 291.1^{\mathrm{b}}\end{array}$ & $\begin{array}{l}C_{1}: 292.14 \\
C_{2}: 291.79 \\
C_{3}: 290.93\end{array}$ & $\begin{array}{l}C_{1}: 291.4^{\mathrm{c}} \\
C_{3}: 290.7^{\mathrm{c}}\end{array}$ & $\begin{array}{c}C_{1}: 291.52 \\
291.23\end{array}$ & $291.7^{\mathrm{b}}$ & 291.51 & $290.6^{\mathrm{d}}$ & 292.95 \\
\hline$\Delta_{\pi}$ & -5.7 & $\begin{array}{l}C_{1}:-5.88 \\
C_{2}:-5.72 \\
C_{3}:-6.04\end{array}$ & $\begin{array}{l}C_{1}:-6.6 \\
C_{2}:-6.6 \\
C_{3}:-6.2\end{array}$ & $\begin{array}{l}\mathrm{C}_{1}:-6.58 \\
\mathrm{C}_{2}:-6.71 \\
\mathrm{C}_{3}:-6.21\end{array}$ & $\begin{array}{l}C_{1}:-5.2 \\
C_{3}:-5.2\end{array}$ & $\begin{array}{l}C_{1}:-6.40 \\
C_{3}:-6.67\end{array}$ & -6.4 & -6.48 & -4.7 & -7.46 \\
\hline$\Delta_{\pi}$ & +3.8 & & +3.1 & & +5.3 & & +3.7 & & +5.5 & \\
\hline
\end{tabular}

${ }^{\mathrm{a}}$ Reference 9 .

${ }^{\mathrm{b}}$ Reference 28.

${ }^{\mathrm{c}}$ Reference 10.

${ }^{\mathrm{d}}$ Reference 11.

TABLE III. Electronic configurations of five azabenzenes in neutral ground state.

\begin{tabular}{ll}
\hline \hline Molecule & Electronic configurations \\
\hline Pyridine & $1 a_{1}^{2} 1 b_{2}^{2} 2 a_{1}^{2} 3 a_{1}^{2} 2 b_{2}^{2} 4 a_{1}^{2} 5 a_{1}^{2} 6 a_{1}^{2} 3 b_{2}^{2} 4 b_{2}^{2} 7 a_{1}^{2} 8 a_{1}^{2} 5 b_{2}^{2} 9 a_{1}^{2} 6 b_{2}^{2} 1 b_{1}^{2} 10 a_{1}^{2} 7 b_{2}^{2} 2 b_{1}^{2} 1 a_{2}^{2} 11 a_{1}^{2}$ \\
Pyrimidine & $1 b_{2}^{2} 1 a_{1}^{2} 2 a_{1}^{2} 2 b_{2}^{2} 3 a_{1}^{2} 4 a_{1}^{2} 5 a_{1}^{2} 3 b_{2}^{2} 6 a_{1}^{2} 4 b_{2}^{2} 7 a_{1}^{2} 8 a_{1}^{2} 5 b_{2}^{2} 9 a_{1}^{2} 1 b_{1}^{2} 6 b_{2}^{2} 10 a_{1}^{2} 1 a_{2}^{2} 2 b_{1}^{2} 11 a_{1}^{2} 7 b_{2}^{2}$ \\
Pyridazine & $1 a_{1}^{2} 1 b_{2}^{2} 2 b_{2}^{2} 2 a_{1}^{2} 3 a_{1}^{2} 3 b_{2}^{2} 4 a_{1}^{2} 5 a_{1}^{2} 4 b_{2}^{2} 5 b_{2}^{2} 6 a_{1}^{2} 7 a_{1}^{2} 8 a_{1}^{2} 6 b_{2}^{2} 1 b_{1}^{2} 7 b_{2}^{2} 9 a_{1}^{2} 2 b_{1}^{2} 1 a_{2}^{2} 10 a_{1}^{2} 8 b_{2}^{2}$ \\
Pyrazine & $1 b_{1 u}^{2} 1 a_{g}^{2} 1 b_{2 u}^{2} 2 a_{g}^{2} 1 b_{3 g}^{2} 2 b_{1 u}^{2} 3 a_{g}^{2} 3 b_{1 u}^{2} 2 b_{2 u}^{2} 2 b_{3 g}^{2} 4 a_{g}^{2} 5 a_{g}^{2} 3 b_{2 u}^{2} 4 b_{1 u}^{2} 4 b_{2 u}^{2} 1 b_{3 u}^{2} 3 b_{3 g}^{2} 1 b_{2 g}^{2} 5 b_{1 u}^{2} 1 b_{1 g}^{2} 6 a_{g}^{2}$ \\
$s$-triazine & $1 e^{\prime 2} 2 e^{\prime 2} 1 a_{1}^{\prime 2} 3 e^{\prime 2} 4 e^{\prime 2} 2 a_{1}^{\prime \prime} 3 a_{1}^{\prime 2} 5 e^{\prime 2} 6 e^{\prime 2} 7 e^{\prime 2} 8 e^{\prime 2} 1 a_{2}^{\prime 2} 4 a_{1}^{\prime 2} 1 a_{2}^{\prime \prime 2} 9 e^{\prime 2} 10 e^{\prime 2} 5 a_{1}^{\prime \prime} 1 e^{\prime \prime 2} 2 e^{\prime \prime 2} 11 e^{\prime 2} 12 e^{\prime 2}$ \\
\hline
\end{tabular}


were obtained using the Slater transition potential (TP) method in combination with a double basis set technique, where we used a normal orbital basis set (see above) in the minimization of the energy, and an added augmented diffuse basis sets $(19 s, 19 p, 19 d)$ for the excited carbon or nitrogen in order to obtain a proper representation of the relaxation effects.

The TP calculation gives most of the relaxation effect upon core ionization but neglects the relaxation effects on the molecular ion core on adding the excited electron. In order to determine the absolute energy position of the spectrum, we resorted to $\Delta \mathrm{Kohn}$-Sham $(\Delta \mathrm{KS})$ calculations as described in Refs. 8 and 24. All the calculated spectra were calibrated so that the first spectral feature corresponding to the transition from the $1 s$ level to the lowest unoccupied molecular orbital (LUMO) coincides with the same one obtained from the $\Delta \mathrm{KS}$ calculations in which the energy difference between the ground state and the relaxed core excited state is calculated. The ionization potentials (IPs) were also calculated in the $\Delta \mathrm{KS}$ scheme where the energy is taken as the difference between the ground state and the fully optimized core-ionized state. Relativistic effects of $+0.3 \mathrm{eV}$ for the $\mathrm{N} 1 s$ edge and $+0.2 \mathrm{eV}$ for the $\mathrm{C} 1 s$ edge $^{24}$ were also included to produce the overall shift of the spectrum.

Both symmetry broken and symmetry restricted calculations have been performed. In general, the molecular point group symmetry is broken, and the core hole localized, upon excitation involving symmetry adapted core orbitals. This follows from pseudo-Jahn-Teller effects operating for the close lying core excited levels that couple through antisymmetric vibrational modes. Computationally, core localization leads to an efficient incorporation of relaxation energy upon the core excitation, which in the symmetry adapted case corresponds to interaction of certain resonant configurations which are not accounted for in the static exchange, or single determinant approximations. While in the symmetry broken case the spectra are calculated within $1 \mathrm{eV}$, symmetry restriction leads to offsets of the order of several eVs. Thus the physical pseudo-Jahn-Teller localization is met by a more accurate calculation in the symmetry broken case. However, for interpretation purposes it can sometimes be desirable to relate observed spectral features to the electronic structure and symmetry of the ground state. We have therefore augmented the symmetry broken, core hole localized calculations, that allocate spectral transitions and intensities, with symmetry restricted calculations to obtain symmetry orbital labels of the peaks.

A Gaussian function [full width at half maximum $(\mathrm{FWHM})=0.3 \mathrm{eV}$ for carbon and nitrogen atoms] was used for convoluting the spectra below the IP. Vibrational and rotational effects are not included in this work.

\section{RESULTS}

Figure 2 shows an overview of the experimental NEXAFS spectra of all the azabenzenes at the nitrogen and carbon $1 s$ edges. The main features have been numbered and will be discussed through the text.

\section{A. $\mathrm{N} 1 \mathrm{~s}$ edge}

The overall gas phase spectrum of pyridine at the $\mathrm{N} 1 s$ edge agrees well with previous synchrotron ${ }^{8}$ and EEL studies, ${ }^{9,10}$ and it is in less agreement with the condensed phase studies of pyridine adsorbed on $\mathrm{Pt}(111),{ }^{7} \mathrm{Cu}(110),{ }^{25}$ $\mathrm{Ag}(111),{ }^{5}$ and $\mathrm{Ni}(111)$ (Ref. 6) where the photoabsorption spectra depend on the grazing incidence angle. Earlier innershell EEL gas phase studies of $s$-triazine at the $\mathrm{N}$ edge ${ }^{11}$ show an agreement with our experimental spectrum, as does the multilayer NEXAFS spectrum of $s$-triazine upon SR excitation recorded by Dudde et al. ${ }^{4}$ For pyridazine the gas phase EEL study in Ref. 10 shows a general agreement with our experimental data.

Our gas phase pyrazine spectrum is consistent with the $\mathrm{N} 1 s$ spectra of the pyrazine adsorbed on a substrate, ${ }^{6,25}$ whereby the results depend on the orientation of the sample. For pyrimidine, there are no previous studies at the $\mathrm{N} 1 s$ edge, however, our gas phase spectrum shows a rough agreement with the condensed phase NEXAFS spectrum of pyrimidinic bases, thymine, and uracil shown in Ref. 26. The enlarged experimental and the calculated NEXAFS spectra of pyridine, pyridazine, pyrimidine, pyrazine, and $s$-triazine at the $\mathrm{N} 1 s$ edge are displayed in Fig. 3. Theoretical spectra are shown under their corresponding experimental counterparts. Peak positions and $\mathrm{N} 1 s$ thresholds for the respective molecules are summarized in Table I. Both experimental and theoretical spectra are dominated by the first peak. Peak 2 in the experimental spectrum of pyrimidine $(399.9 \mathrm{eV})$, pyridazine $(399.6 \mathrm{eV})$, and $s$-triazine $(399.9 \mathrm{eV})$ seems to be without counterpart in the pyrazine and pyridine spectra. This peak is well reproduced by our calculations for the pyrimidine and pyridazine spectra but has no equivalent in the calculated $s$-triazine spectrum. There are no studies for pyrimidine, however, the $s$-triazine EEL study of Ref. 11 reveals the same shoulder at $400.5 \mathrm{eV}$. Peak 3 in the computed spectra of pyrazine, pyridine, pyridazine, and pyrimidine is not present in the experimental spectra recorded here. Next peak at approximately $402.8 \mathrm{eV}$ in the experimental spectra and labeled as number 4, is seen to be asymmetric in all molecules (see Figs. 2 and 3). Close to the experimental IP of each molecule we find peak 5 . It is clearly seen in pyrimidine and $s$-triazine, and it is less intense for pyrazine, pyridine, and pyridazine. Peak 5 in the calculated spectra is partly accounted by the stepwise feature at approximately $405 \mathrm{eV}$ for all molecules. Above threshold two broad and structureless features are named as peaks 6 and 7 (see Fig. 2). Peak 6 is present in the five experimental spectra, while 7 is recorded for pyridazine, pyrimidine, pyrazine, and $s$-triazine molecules. There is very little change in the peak position of the first and second resonances in the five molecules. Also peaks 4-7 are present although displaced from each other. These similarities between the five spectra indicate that the local atomic structure is the dominant factor in influencing the spectra.

From Fig. 3 we observe that the most intense experimental features have been nicely reproduced by the present calculations. Table I summarizes the assignments of peaks evaluated via the TP calculations with imposing symmetry, 

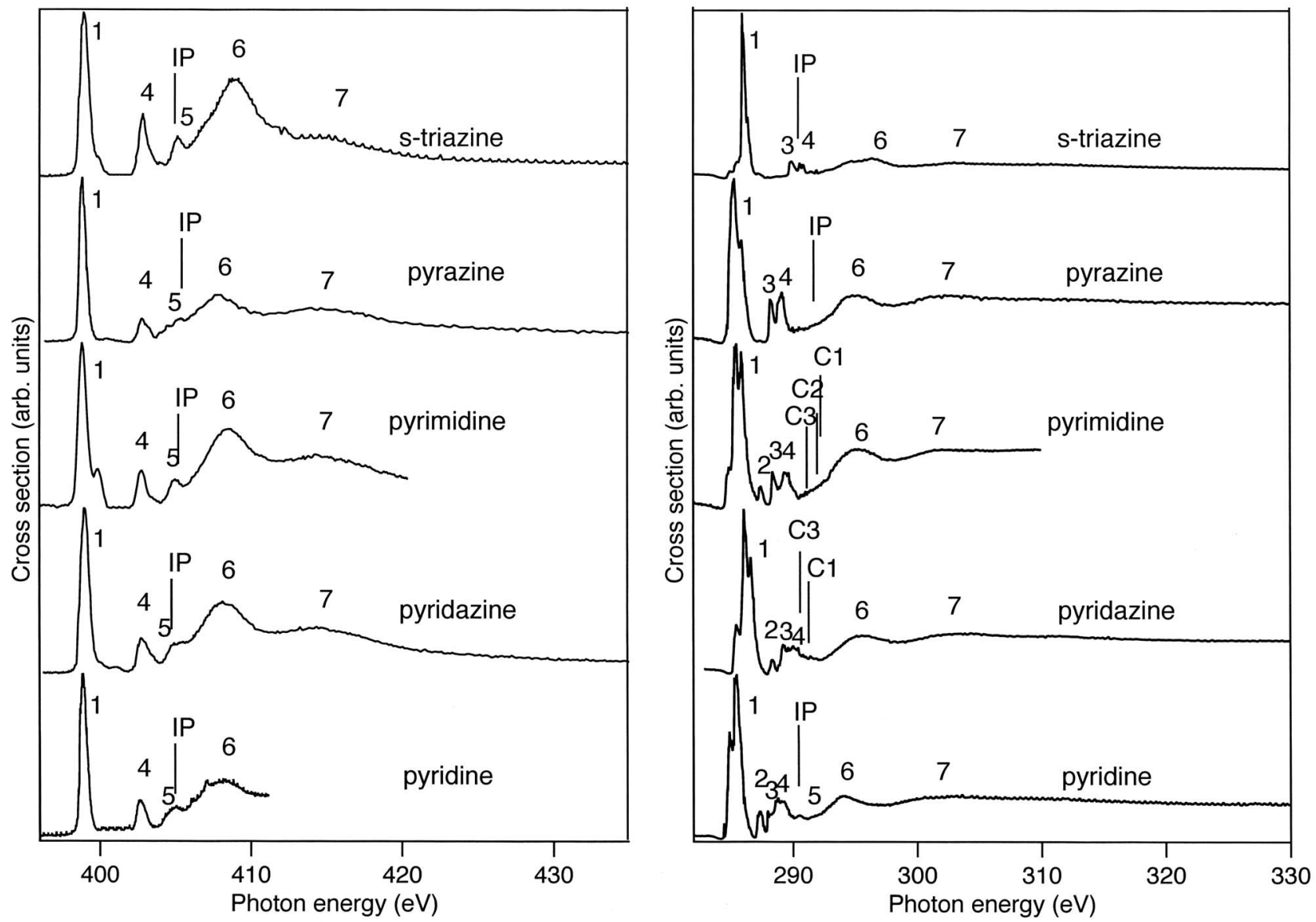

FIG. 2. Overview of the experimental NEXAFS spectra of the five azabenzenes at the nitrogen $1 s$ (left) and carbon $1 s$ edges (right). The main features are numbered for both edges for future reference in the text. The numbering in the $\mathrm{C} 1 \mathrm{~s}$ edge does not consider the splitting of the resonances and a more accurate numbering is given in the enlarged figures. For pyrimidine and pyridazine the energy position of the respective $\mathrm{C} 1, \mathrm{C} 2$, and $\mathrm{C} 3$ edges is shown. The energy scale is calibrated as described in Sec. II. The zig-zag pattern in the $s$-triazine spectrum at the $\mathrm{N} 1 s$ edge is due to gap changes that were not optimal and were not cancelled by normalization.

as well as the calculated IP and the term values, $\Delta_{\pi}=\mathrm{IP}$ $-E\left(\pi^{*}\right)$ at the $\mathrm{N} 1 s$. All the values were calculated using the $\Delta \mathrm{KS}$ scheme with the correction of relativistic effects $(+0.3 \mathrm{eV})$. Table I also summarizes the experimental energy positions of the assigned peaks, the experimental IP values measured in this work, as well as the experimental term values $\Delta_{\pi}$ and $\Delta_{\sigma}=\mathrm{IP}-E\left(\sigma^{*}\right)$.

\section{B. C $1 s$ edge}

In contrast to the $\mathrm{N}$ edge (see Fig. 2), upon substitution of $\mathrm{CH}$ groups by $\mathrm{N}$ atoms, the number of resonances in the $\mathrm{C}$ edge differs from one molecule to the other. The overall experimental spectra of $s$-triazine and pyridine agree well with the gas phase studies of $s$-triazine in Ref. 11, with gas phase studies of pyridine in Refs. 8-10 and multilayer films of pyridine in Refs. 6 and 7. Our experimental spectrum for pyridazine agrees well with the EEL spectrum of pyridazine in the gas phase ${ }^{10}$ and shows an overall agreement with the condensed phase study in Ref. 6. In Fig. 4 we show the enlarged experimental and the calculated NEXAFS spectra at the $\mathrm{C} 1 s$ edge for the five molecules studied here.

Peak 1 is present in all molecules; it is the strongest in the spectrum as expected from the insaturation of the bonds in the molecules. Except for $s$-triazine peak 1 is split in two, three, or four components. Peak 2 is present in the experimental spectra of pyridazine, pyrimidine, and pyridine and is well reproduced by our calculations. Peaks 3-5 lie right below the IP confirming the valence/Rydberg nature of the peaks. Observe that peak 4 is split in two components for pyridine and pyrimidine. Finally, peak numbers 6 and 7 lie above the threshold (see Fig. 2). Peak 6 is clearly seen in all the experimental spectra of these molecules. Peak 7 is barely seen for all five molecules and is much weaker than the corresponding peak at the $\mathrm{N} 1 s$ edge. Again, our calculations describe most of the experimental features that lie below the theoretical IP. Slight differences may arise from vibronic contributions not accounted for in this work. Table II summarizes the assignments of peaks by means of the symmetry restricted TP calculations, the experimental and calculated IPs and the term values at the $\mathrm{C} 1 s$. All the theoretical values were calculated using the $\Delta \mathrm{KS}$ scheme and included the relativistic effects $(+0.2 \mathrm{eV})$. Table II also shows the experimental energy positions of the resonances, as well as the experimental term values.

\section{DISCUSSION}

Azabenzenes, like other unsaturated compounds, in general, exhibit a common fourfold pattern in their NEXAFS 
spectra; a strong $\pi^{*}$ resonance plus a weak Rydberg series in the discrete part and multielectron excitations superimposed on a shape resonance structure in the near-continuum part. These features are scrambled by the chemical shifts of the symmetry for inequivalent core sites. While these energy shifts are quite small - a few tenths of an $\mathrm{eV}$ - the site variation of the intensities is quite significant. ${ }^{29}$ One also finds that the chemical shifts of the $\pi^{*}$ excitations are closely related to the electronegative character of the substituent groups. The occurrence of multiple $\pi^{*}$ and $\sigma^{*}$ resonances is apparent in aromatic compounds but often one finds evidence for only one strong such resonance $\left(\pi^{*}\right.$ and $\left.\sigma^{*}\right)$ per core site.

Before the discussion, we give the electronic configurations of the five azabenzenes in their neutral ground state in Table III. The allowed dipole electronic transitions $1 \mathrm{~s}$ $\rightarrow \psi_{\text {unoccupied orbital }}$ can be easily acquired with the help of group theory.

\section{A. $\mathrm{N} 1 s$ edge}

In all the spectra presented in Figs. 2 and 3, the first peak is assigned to the transition of the $1 s$ electron in the $\mathrm{N}$ atom to the lowest unoccupied $\pi^{*}$ antibonding molecular state and it occurs at about $398 \mathrm{eV}$ in the experimental spectra. It is well reproduced by our theoretical calculations that place the peak at an average of $0.5 \mathrm{eV}$ lower than the experimental value. Since all $\mathrm{N}$ atoms are in symmetric positions in pyrazine, pyridazine, $s$-triazine, and pyridine, the peak is not split due to the chemical shift. The asymmetry on the high energy side is due to vibrational excitations, that, in turn, are due to the antibonding $\pi^{*}$ character of the excited orbital. ${ }^{8}$

The contributions (area under the peak normalized to the total area in percent) of this peak to the total $K$-shell intensity spectrum for each molecule are $7 \%, 10 \%, 13 \%, 9 \%$, and $9 \%$ $( \pm 1 \%)$ for pyridine, pyridazine, pyrimidine, pyrazine, and $s$-triazine, respectively. The experimental results for pyridine, pyrazine, and $s$-triazine are in agreement with the theoretical results in this work which are $8 \%, 9 \%$, and $8 \%$ for pyridine, pyrazine, and $s$-triazine, respectively. However, the results for pyridazine and pyrimidine are higher than the corresponding theoretical ones, $9 \%$ and $8 \%$. We have also compared the width of the peak (FWHM) for all the molecules with the following results, 0.56, 0.66, 0.73, 0.52, and $0.70 \mathrm{eV}$ for pyridine, pyridazine, pyrimidine, pyrazine, and $s$-triazine, respectively (see Fig. 3). The results of pyridine and pyrazine agree with those given in Ref. 6 . In the same study, a broadening of the $\mathrm{N} 1 s \rightarrow \pi^{*}$ peak by a factor of 2 for monolayers of pyridine was observed. This would suggest that the environment where the molecules are; (a) surrounded by molecules of the same kind (condensed phase and gas phase as in our case) or (b) surrounded by foreign molecules (metal substrate); plays an important role in the shape of the NEXAFS spectrum.

Peak 2 corresponds to a transition to the LUMO+1 and it has $\pi^{*}$ symmetry. In pyridine, the transition from $1 s\left(a_{1}\right)$ orbital of nitrogen to $\mathrm{LUMO}+1\left(a_{2}\right)$ is dipole forbidden in the $C_{2 v}$ symmetry. $^{8}$ It is discussed in Ref. 8 that this peak localized at $400.2 \mathrm{eV}$ in their pyridine spectrum regains in- tensity through the vibronic coupling. Our present calculations for the pyridine molecule do not show any structure for peak 2 in perfect agreement with the experimental data. For pyrimidine and pyridazine, the LUMO +1 has $b_{2}$ symmetry to which the transition $1 s\left(a_{1}\right) \rightarrow \pi^{*}\left(b_{2}\right)$ is not forbidden in the $C_{2 v}$ symmetry and, thus, the present calculations, as well as the experimental spectra for pyrimidine and pyridazine, show a strong resonance at $399.9 \mathrm{eV}$ for pyrimidine and a weaker resonance at $399.6 \mathrm{eV}$ for pyridazine.

In the ground state, the LUMO and LUMO+ 1 molecular orbitals in $s$-triazine are degenerate with symmetry $e^{\prime \prime}$, but after exciting the $1 s$ electron into LUMO or LUMO+1, the excitation energies and intensities are rather different and the peaks become separable. However, the transition of the $1 \mathrm{~s}$ electron in any of the $\mathrm{N}$ atoms of the molecule to the $\mathrm{LUMO}+1$ orbital is much lower in intensity compared to the LUMO transition due to this core hole effect, and thus peak 2 is not visible in the computed spectra. However, it is visible in the experimental results due to the vibronic contribution.

Peaks 3 and 4 correspond to excitations to Rydberg or mixed valence-Rydberg orbitals with some antibonding character of both $\sigma^{*}$ and $\pi^{*}$ symmetries. Peak 3 is not visible experimentally and gets sizable intensity only in the theoretical spectrum of pyridine and pyridazine. On the other hand, peak 4 is present in all experimental and theoretical spectra. Furthermore, in pyridine peak 4 shows an admixture of Rydberg character, which is underestimated in the TP calculation (but is improved in the $\Delta \mathrm{KS}$ calculation). One may also find that the order of some unoccupied orbitals may change in excitation. The LUMO +6 of pyrimidine, pyridazine, and pyrazine, LUMO +5 of $s$-triazine in their ground states have become $\mathrm{LUMO}+3$ and $\mathrm{LUMO}+2$, respectively, in the symmetry restricted TP calculations, indicating that peak 4 corresponds to a transition from $\mathrm{N} 1 s$ to LUMO+3 for pyrimidine, pyridazine, and pyrazine but to LUMO+2 for $s$-triazine. Notice that the intensity of this peak compared to the absorption continuum increases with the addition of $\mathrm{CH}$ groups in the molecule. If we look at the experimental spectra for the $\mathrm{N} 1 s$ edge in Fig. 2 and calculate the intensity difference between peak 4 and the intensity at the far continuum, we observe that pyridazine and pyrazine have significantly lower values compared to $s$-triazine.

The highest intensity difference is for the $3 \mathrm{~N}$ atoms containing molecule, $s$-triazine, while the two molecules with two $\mathrm{N}$ atoms substituted have lower intensity values. These results corroborate the fact that the addition of $\mathrm{CH}$ groups in the molecule enhances the Rydberg resonances when compared to the continuum. This trend was seen for small molecules in $\mathrm{CO},{ }^{30} \mathrm{H}_{2} \mathrm{CO},{ }^{31}$ and $\mathrm{CH}_{3} \mathrm{OH}$ (Ref. 32) and from this study is postulated to be applicable to larger organic molecules.

Close to the IP we find peak 5. In the study of the pyridine molecule, Kolczewski et $a .^{8}{ }^{8}$ assigned this peak as an admixture of valence and Rydberg-type transitions. However, it has been seen in the $\mathrm{N}_{2}$ molecule, first theoretically by Arneberg et al. ${ }^{33}$ and later on experimentally by Neeb et al. ${ }^{34,35}$ that there are double excitations just at the $\mathrm{N} 1 s$ IP. Thus peak 5 in our spectra could have a double excitation 

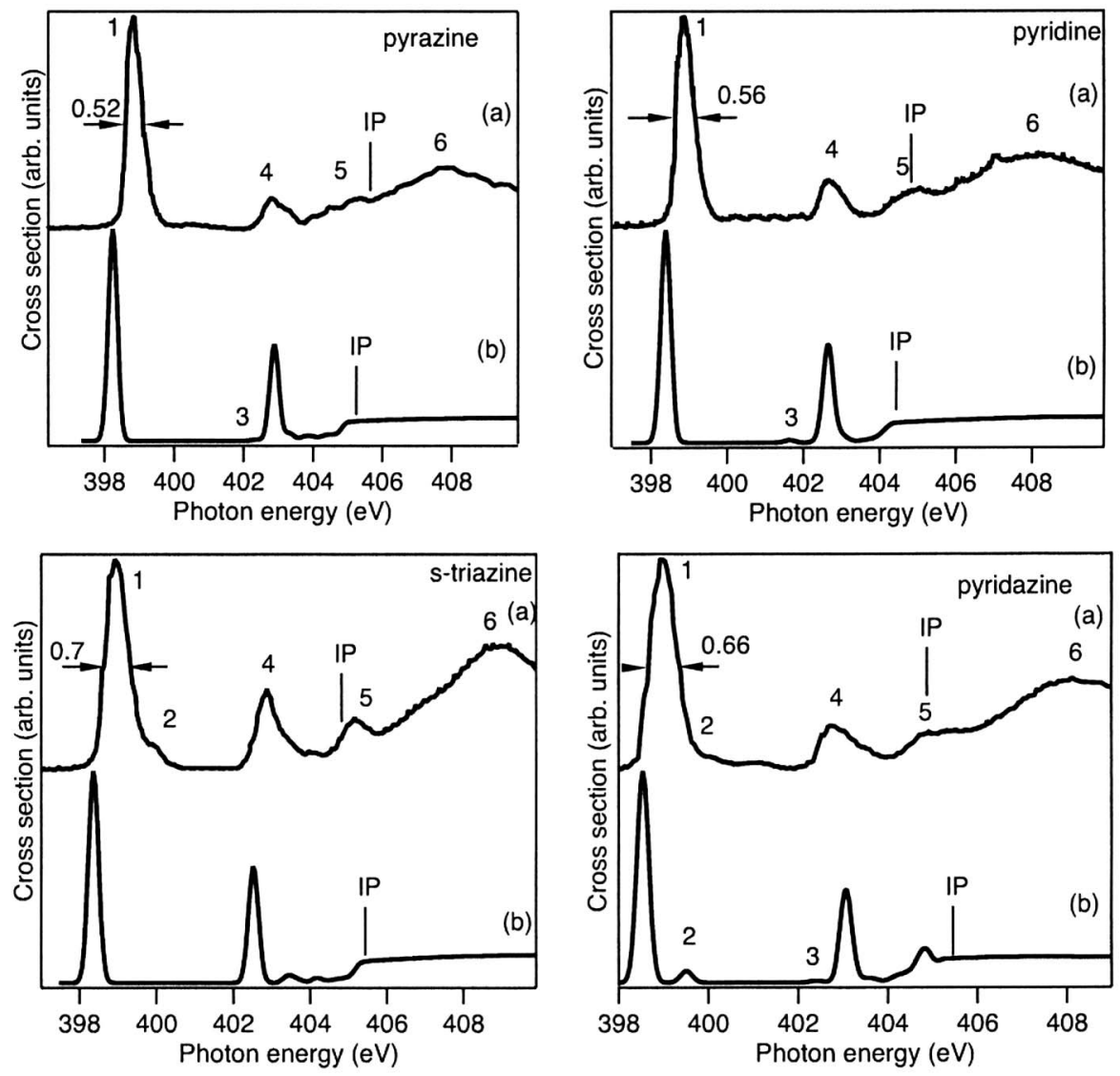

FIG. 3. Comparison of the experimental (a) and calculated (b) gas phase NEXAFS spectra of pyridine, pyridazine, pyrimidine, pyrazine, and $s$-triazine at the nitrogen $1 s$ edge. Peak positions as well as the $\mathrm{N} 1 s$ thresholds (IP) are shown here and summarized in Table I.

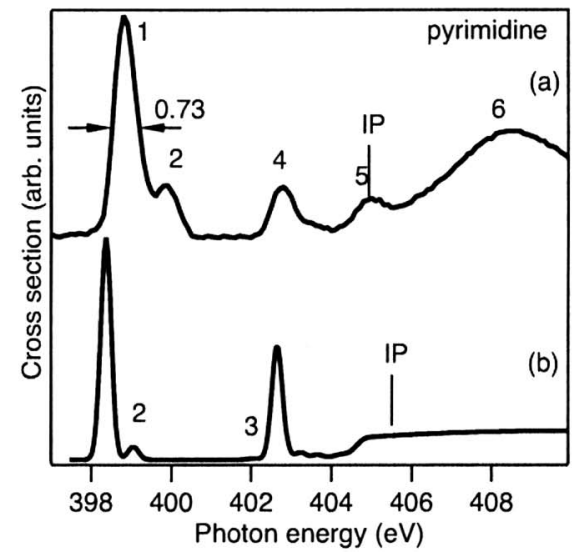

origin (the excitation of the $\mathrm{N} 1 s$ electron is accompanied by a simultaneous excitation of a valence electron), namely, core-valence doubly excited states. This is in agreement with Ref. 11 who assign this peak to double excitations. In our calculation only one-electron excitations are considered, thus, peak 5 cannot be present in the theoretical spectra if this interpretation is correct. However, we cannot exclude peaks originated from double excitation mechanisms in our experimental spectra before or after the IP threshold.

Above the $1 s$ IP the $K$-shell spectra of all five molecules show two resonances, peaks 6 and 7 assigned to excitations to the $\sigma^{*}$ orbitals in agreement with Refs. 4 and $7-11$. Furthermore, Apen et al. ${ }^{11}$ and Hannay et al. ${ }^{10}$ assigned both peaks to the $\mathrm{N} 1 s \rightarrow \sigma_{\mathrm{C}-\mathrm{N}}^{*}$ transition. As seen in Fig. $2, \sigma^{*}$, or peak number 6 peaks at different positions for different molecules in the following order: pyrazine $(408.0 \mathrm{eV})$
$<$ pyridine $(408.1 \mathrm{eV})<$ pyridazine $(408.4 \mathrm{eV})<$ pyrimidine $(408.7 \mathrm{eV})<s$-triazine $(409.0 \mathrm{eV})$. This gives rise to a different term values, $\Delta_{\sigma}$ for each of them (see Table I) and a spread of $\Delta_{\sigma}$ equal to $1.7 \mathrm{eV}$.

\section{B. C $1 s$ edge}

Similar to the $\mathrm{N} 1 s$ edge, in all the $\mathrm{C} 1 s$ spectra presented in Figs. 2 and 4, the first peak is assigned to the transition of the $1 s$ electron in the $\mathrm{C}$ atom to a $\pi^{*}$ antibonding molecular orbital. It occurs at roughly $285 \mathrm{eV}$ in all the carbon experimental spectra. It is well reproduced by our theoretical calculations that place the peak at an average value of $0.3 \mathrm{eV}$ lower than the experimental value. Due to the different environments for different carbon atoms in the molecules peak 1 is split. Peak $1^{\prime}$ in pyridazine is mostly due 

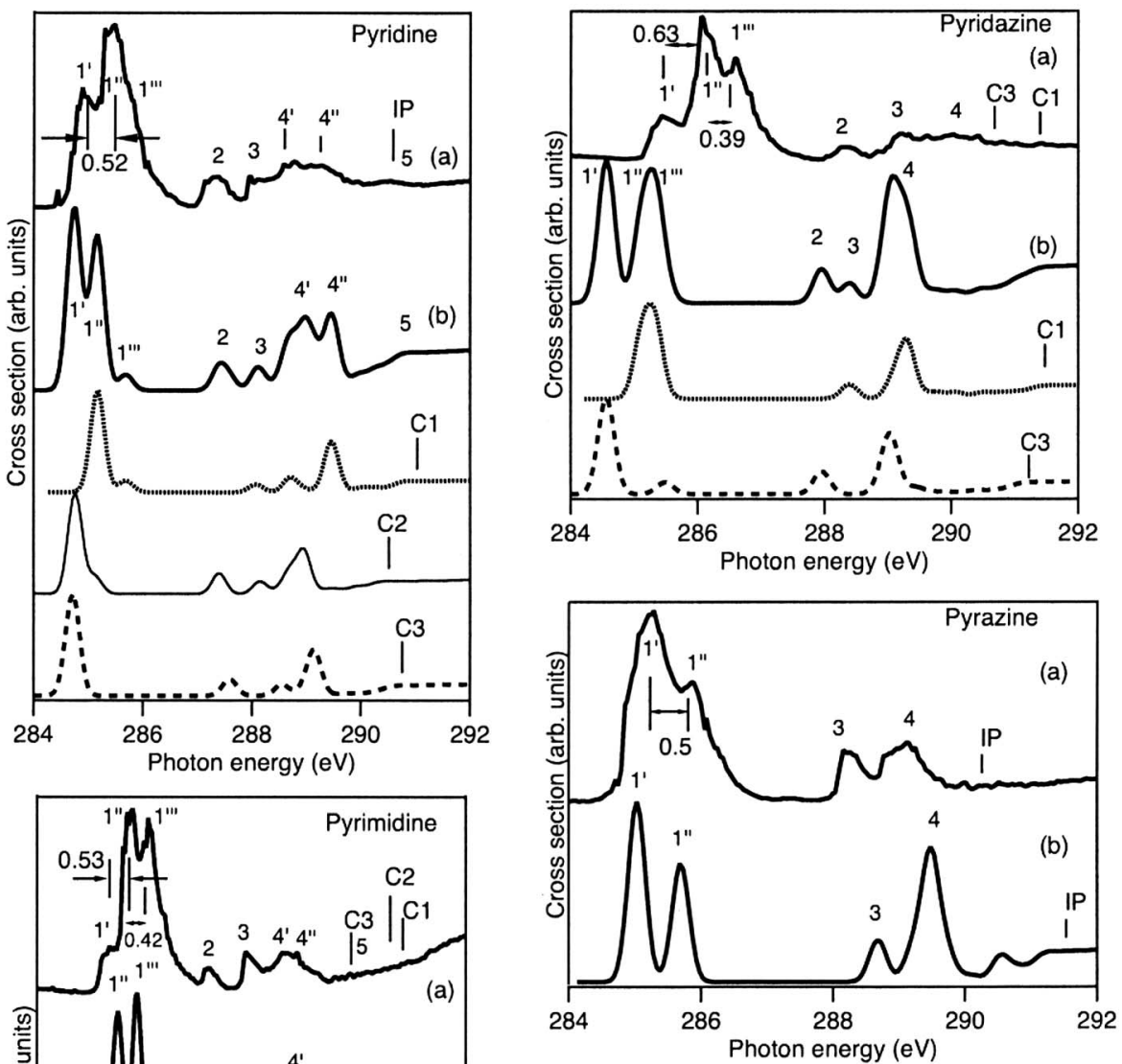

(a)
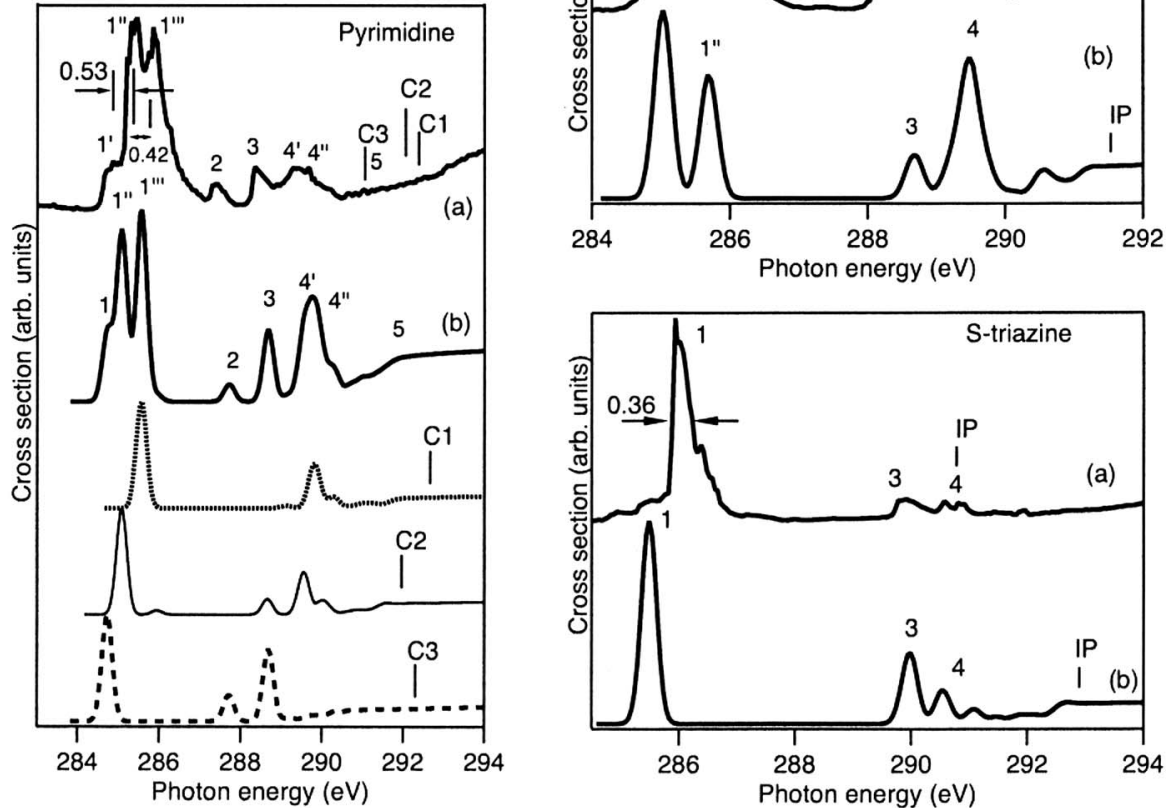

FIG. 4. Comparison of the experimental (a) and calculated (b) gas phase NEXAFS spectra of pyridine, pyridazine, pyrimidine, pyrazine, and $s$-triazine at the carbon $1 s$ edge. Peak positions as well as the $\mathrm{C} 1 s$ thresholds (IP or C1, C2, C3 edges) are shown here and summarized in Table II. to the $\mathrm{C}_{3}$ atom and corresponds to a transition of the $1 s\left(b_{2}\right)$ electron in the $\mathrm{C}$ atom to the LUMO with $\pi^{*}\left(a_{2}\right)$ symmetry (see Fig. 1 for the numbering of atoms and Fig. 4 for the spectra). Peak $1^{\prime \prime}$ has contribution from $\mathrm{C}_{1}, \mathrm{C}_{3}$, with $\mathrm{C}_{1}$ being the largest contributor (see Table II). It is formed by a superposition of transitions to the LUMO and LUMO +1 orbitals. Peak $1^{\prime}$ in pyrimidine is due to a transition from $1 s\left(a_{1}\right)$ electron in the $\mathrm{C}_{3}$ atom to the $\operatorname{LUMO}\left(b_{1}\right)$ (see Fig. 4). $1^{\prime \prime}$ is a pure LUMO transition of the $1 s\left(b_{2}\right)$ electron in the $\mathrm{C}_{2}$ atom with $a_{2}$ symmetry, while $1^{\prime \prime \prime}$ is entirely due to the $\operatorname{LUMO}\left(b_{1}\right)$ transition of the $\mathrm{C}_{1}$ atom. ${ }^{36}$ Finally, the shoulder in the high energy side of 1 '"' is ascribable to a transition of the $\mathrm{C}_{2} 1 s\left(a_{1}\right)$ to the $\mathrm{LUMO}+1\left(b_{1}\right)$ orbital. In pyridine both $1^{\prime}$ and $1^{\prime \prime}$ peaks are due to LUMO transitions of the $1 s\left(a_{1}\right)$ electron. $1^{\prime}$ corresponds to transitions in the $\mathrm{C}_{2}$ and $\mathrm{C}_{3}$ positions to orbitals of $\pi^{*}\left(b_{1}\right)$ symmetry and $1^{\prime \prime}$ corresponds to transitions in the $\mathrm{C}_{1}$ position with $\pi^{*}\left(b_{1}\right)$ symmetry and $\mathrm{C}_{2}$ position with $\pi^{*}\left(a_{s}\right)$ symmetry. The shoulder named $1^{\prime \prime \prime}$ (see Fig. 4) is a $\mathrm{LUMO}+1\left(a_{2}\right)$ transition of the $1 s\left(b_{2}\right)$ electron in the $\mathrm{C}_{1}$ atom also in agreement with Ref. 8. All the carbon atoms in pyrazine are equivalent, thus the splitting of peak 1 is due to transitions to two different molecular orbitals. 1' corresponds to the $\operatorname{LUMO}\left(\pi^{*}\left(b_{3 u}\right)\right)$ transition and $1^{\prime \prime}$ to the LUMO $+1\left(a_{u}\right)$. Similar to pyrazine, the three carbon atoms in $s$-triazine are analogous, thus the peak is not split and peak 1, corresponds to a transition to the LUMO with $\pi^{*}\left(e^{\prime \prime}\right)$ symmetry also in agreement with Ref. 11 . The asymmetry on the high energy side of the $\pi^{*}$ resonance in the experimental spectra and disagreements of the relative intensities of peaks between experimental and theoretical spectra is due to the vibronic coupling. Since we have not included vibrational effects in our calculations, the theoretical spectra do not reproduce these features.

The shift in atomic core-level energy due to a specific chemical environment can be explained with the higher electronegativity of the $\mathrm{N}$ atom compared to the $\mathrm{C}$ atom. The $\mathrm{C}$ 
atoms that are bound directly to the nitrogen are weakly positive, i.e., the electron cloud is partially displaced over the $\mathrm{N}$ atom and more energy is required for the $\mathrm{C} 1 s$ ionization when compared to the $\mathrm{C}$ atoms that lie further away from the $\mathrm{N}$ atom. Pyrimidine provides a good example of this notion. According to Fig. 1 the $\mathrm{C}_{1}$ position is the most positive, and thus the one that will require the largest amount of energy for the $\mathrm{C} 1 s$ to be ionized. If we now look at Fig. 4, we see that $\mathrm{C}_{1}$ is indeed the highest in energy position, meaning that $292.14 \mathrm{eV}$ are needed to ionize its $1 \mathrm{~s}$ electron when compared to $\mathrm{C}_{2}$ or $\mathrm{C}_{3}$ which need 291.79 and $290.93 \mathrm{eV}$, respectively. This is also confirmed by the measured $\mathrm{C} 1 s$ thresholds listed in Table II. The $\mathrm{C}_{1}, \mathrm{C}_{2}$, and $\mathrm{C}_{3}$ of pyrimidine are measured at 292.4, 292.0, and $291.1 \mathrm{eV},{ }^{28}$ respectively. We have also compared the width (FWHM) of the C $1 s \rightarrow \pi^{*}$ peak for $s$-triazine and the energy splitting of the C $1 s$ $\rightarrow \pi^{*}$ peak for the other molecules. We find that the splitting between $1^{\prime}$ and $1^{\prime \prime}$ in pyridine is $0.52 \mathrm{eV}$, and $0.50 \mathrm{eV}$ for pyrazine. The splitting of $1^{\prime}$ and $1^{\prime \prime}$ for pyridazine are 0.63 and $0.39 \mathrm{eV}$ for $1^{\prime \prime}$ and $1^{\prime \prime \prime}$. The same splittings for pyrimidine give 0.53 and $0.42 \mathrm{eV}$ values. The FWHM measured of peak 1 for $s$-triazine is $0.36 \mathrm{eV}$ as shown in Fig. 4. The results of $1^{\prime}$ and $1^{\prime \prime}$ splitting in pyridine and pyrazine were compared to those presented in Ref. 6 that relate 0.55 and $0.81 \mathrm{eV}$ for multilayer pyridine and pyrazine, respectively. As seen from these values, the C $1 s \rightarrow \pi^{*}$ peak splitting in pyridine is in agreement with Ref. 6 . However, for the pyrazine molecule we measured a splitting of $0.50 \mathrm{eV}$, much narrower than in multilayer pyrazine of Ref. 6. Upon comparison of the values with the FWHM of the $\mathrm{N} 1 s \rightarrow \pi^{*}$ transition, we observe that the values measured for the $\mathrm{C} 1 \mathrm{~s}$ edge are, in general, smaller than those in the $\mathrm{N} 1 s$ edge. This would imply that vibrational modes are more active in the $\mathrm{N} 1 s \rightarrow \pi^{*}$ transition than in the $\mathrm{C} 1 s$ edge.

The results of the calculations for peaks 2 and 3 suggest specific spectral assignments as follow; both resonances correspond to a transition of the $\mathrm{C} 1 s$ electron to a $\sigma^{*} / \pi^{*}$ mixed symmetry orbitals. Thus, in pyrimidine, peak 2 corresponds to a transition to the $\mathrm{LUMO}+2\left(\sigma^{*}\left(a_{1}\right)\right)$ of the $\mathrm{C}_{3} 1 s$ electron and peak 3 to a transition to $\mathrm{LUMO}+2\left(\sigma^{*}\left(a_{1}\right)\right)$ from $\mathrm{C}_{2} 1 s$ and LUMO $+3\left(\pi^{*}\left(b_{2}\right)\right)$ from $\mathrm{C}_{3} 1 s$. In pyridazine, peak 2 corresponds to a LUMO $+2\left(\sigma^{*}\left(a_{1}\right)\right)$ transition of the $1 s$ electron in the $\mathrm{C}_{3}$ atom and peak 3 the same but in the $\mathrm{C}_{1}$ atom. In pyridine, peak 2 is an admixture of transitions to LUMO $+2\left(\sigma^{*}\left(a_{1}\right)\right)$ of the $1 s$ electron in the $\mathrm{C}_{2}$ and $\mathrm{C}_{3}$ atoms and peak 3 corresponds to transitions to $\mathrm{LUMO}+2,+3$ orbitals from the $1 s$ electron in the $\mathrm{C}_{1}$ and $\mathrm{C}_{2}$ atoms with $\sigma^{*}\left(a_{1}\right)$ and $\sigma^{*}\left(b_{2}\right)$ symmetry, respectively. Finally peak 3 in $s$-triazine is an admixture of $\sigma^{*}\left(a_{2}^{\prime \prime}\right)$ and $\pi^{*}\left(a_{1}^{\prime}\right)$.

Peaks $4,4^{\prime}$, and $4^{\prime \prime}$ correspond to excitations to a mixture of Rydberg and hydrogen-derived antibonding orbitals of $\sigma^{*}$ and $\pi^{*}$ symmetries as also seen at the $\mathrm{N} 1 s$ edge. In the experimental spectrum of pyridine this peak consists of two components split by about $0.6 \mathrm{eV}$ compared to the $0.72 \mathrm{eV}$ split in the theoretical spectra. In pyridine the $4^{\prime}$ and $4^{\prime \prime}$ resonances have $\pi^{*}$ symmetry. $4^{\prime}$ is mainly due to the $1 \mathrm{~s}$ electron of the $\mathrm{C}_{2}$ atom to the LUMO+8(a $)$ and $4^{\prime \prime}$ is due to the $1 s$ electron of $\mathrm{C}_{1}$ to the $\mathrm{LUMO}+8\left(a_{1}\right)$ and the $1 s$ electron in the $\mathrm{C}_{3}$ atom to the LUMO+7(a $\left.a_{1}\right)$ orbital in the mol- ecule (see Fig. 4 and Table II for the symmetry assignments). In pyrimidine's experimental spectrum peaks $4^{\prime}, 4^{\prime \prime}$ are apart by $0.3 \mathrm{eV}$ compared to the $0.79 \mathrm{eV}$ in the theoretical spectrum. For pyrimidine, $4^{\prime}$ is due to LUMO $+3,+4$ transitions of the $\mathrm{C}_{1}$ and $\mathrm{C}_{2} 1 s$ electrons. The molecular orbitals have both $\sigma^{*}$ and $\pi^{*}$ symmetries. $4^{\prime \prime}$ in pyrimidine is due to the LUMO +7 transition of the $\mathrm{C}_{1} 1 s$ electron with $\pi^{*}\left(a_{1}\right)$ symmetry. Pyridazine has only one 4 peak ascribed to the transition of the $1 s$ electron from the $\mathrm{C}_{1}$ and $\mathrm{C}_{3}$ atoms to LUMO $+4\left(\pi^{*}\left(a_{2}\right)\right)$ orbital. The main contribution to peak 4 in pyrazine is from the transition to LUMO $+3,+4$ in any of the $\mathrm{C}$ atoms and this orbital has mixed $\sigma^{*}$ and $\pi^{*}$ character. In $s$-triazine, peak 4 is due to the transition of the $1 s$ electron to a LUMO+4 orbital which has $\sigma^{*}\left(e^{\prime}\right)$ symmetry.

Around the C $1 s$ IP value we find peak 5. A double excitation process for the benzene and $s$-triazine molecules was argued to be the source of this peak in the studies made by Rennie et $a l^{37}$ and Apen et al., ${ }^{11}$ respectively. Double excitation processes are not included in our calculation, thus, the nature of peak 5 in the experimental spectra could be partially assigned to excitations of two electrons to nonRydberg orbitals.

Above the $1 s$ IP the $K$-shell spectra of all five molecules show one major resonance, peak 6 and a weak resonance well above the IP, peak 7. Both resonances are assigned to excitations to the $\sigma^{*}$ orbitals or shape resonances. Reference 10 attributes peak 6 to an admixture of $\sigma_{\mathrm{C}-\mathrm{H} / \mathrm{C}-\mathrm{N} / \mathrm{C}-\mathrm{C}}^{*}$ excitations for pyridazine, while in the $s$-triazine would correspond to a $\sigma_{\mathrm{C}-\mathrm{N}}^{*}$ transition. Again as seen in Fig. 2 and Table II, feature 6 peaks at different positions for different molecules in the following order: pyridine $(294.4 \mathrm{eV})<$ pyrazine $(295.4 \mathrm{eV})<$ pyrimidine $(295.5 \mathrm{eV})<$ pyridazine $(296.0 \mathrm{eV})$ $<s$-triazine $(296.1 \mathrm{eV})$.

\section{Term values}

In the overview given above of the resonances encountered in the $\mathrm{C}$ and $\mathrm{N}$ atom $K$-shell spectra, the $\pi^{*}$ resonances are the lowest in energy, followed by Rydberg and/or hydrogen-derived resonances, and at higher energies we encounter $\sigma^{*}$ resonances which could be of Rydberg or mixed valence Rydberg character. As seen in the previous section, a $K$-shell resonance corresponds to a transition from a particular $1 s$ orbital of a specific atom in the molecule to a molecular orbital (MO) that is delocalized over the bonded pair of atoms. Consequently, transitions to the same MO can be reached by $1 s$ electrons of either excited atom participating in the bond. According to Fig. 1 the possible bonded pair of atoms in these azabenzenes can be $\mathrm{C}-\mathrm{C}$ or $\mathrm{C}-\mathrm{N}$ with the corresponding $Z$ numbers of 12 or 13 , respectively. It is to be expected that the $\pi^{*}$ resonance position relative to the respective $1 s$ IP should be rather similar at different $K$ edges (within $\pm 1 \mathrm{eV}$ ), despite the fact that absolute excitation energies are different. ${ }^{30,38}$ One way to corroborate this fact is calculating the $\Delta_{\pi}$ and the spread of $\Delta_{\pi}$ for the five molecules at both edges. Because the $\mathrm{N}$ atoms are equivalent in all five molecules (see Fig. 1) the calculation of $\Delta_{\pi}$ and $\Delta_{\pi}$ spread at the $\mathrm{N} 1 s$ edge is straight forward. From Table I we observe that the experimental $\Delta_{\pi}$ spread at the $\mathrm{N}$ edge is 
$0.9 \mathrm{eV}$, in agreement with the theoretical value of $1.05 \mathrm{eV}$. However, the $\Delta_{\pi}$ spread at the C $1 s$ edge is more complex due to the fact that the $\mathrm{C}$ atoms occupy nonequivalent positions in some of the molecules. For example, peak $1^{\prime}$ in pyrimidine is due to the $C_{3}$ atom which is bonded to another $\mathrm{C}$ atom thus $Z=12$, but $1^{\prime \prime \prime}$ peak in the same molecule is due to the $\mathrm{C} 1$ atom which is bonded to a $\mathrm{N}$ atom, therefore $Z$ $=13$. The $\Delta_{\pi}$ spread for the theoretical values with $Z=12$ is calculated to be $0.95 \mathrm{eV}$ and for $Z=13,1.58 \mathrm{eV}$. From the $\Delta_{\pi}$ values in Table II we obtain an experimental $\Delta_{\pi}$ spread of $1.0 \mathrm{eV}$, for $Z=12$ and 1.9 for $Z=13$. From these values we observe that the position of the $\pi^{*}$ resonance with respect to the IP is within $1 \mathrm{eV}$ for the $\mathrm{N}$ edge in both theoretical and experimental values, also for the theoretical and experimental values at the $\mathrm{C}$ edge for $Z=12$ of the bonded pair of atoms, however, it is a little bit over $1 \mathrm{eV}$ for $Z=13$ for both theoretical and experimental $\Delta_{\pi}$ spread values.

Compared to the rather similar position of the $\pi^{*}$ resonance, the $\sigma^{*}$ resonance shows a different behavior with the particularity that the average $\Delta_{\sigma}$ at the C $1 s$ edge is $0.9 \mathrm{eV}$ higher than the $\mathrm{N} 1 s$ edge. The scatter of the experimental $\Delta_{\sigma}$ energies is $1.7 \mathrm{eV}$ at the $\mathrm{N} 1 \mathrm{~s}$ edge and $1.7 \mathrm{eV}$ for $Z=13$ and $2.2 \mathrm{eV}$ for $Z=12$ at the $\mathrm{C} 1 \mathrm{~s}$ edge. From these values we can conclude that the spread in $\Delta_{\sigma}$ decreases with increasing $Z$. This result was already seen for diatomic and some linear polyatomic molecules ${ }^{39}$ and confirmed here for these heterocyclic molecules.

\section{CONCLUSIONS}

We have investigated the NEXAFS spectra for five azabenzenes at the $\mathrm{N} 1 s$ and $\mathrm{C} 1 s$ edges via experiments and calculations. The experimental and theoretical spectra at the $\mathrm{N}$ and $\mathrm{C} 1 s$ edges show a strong $\pi^{*}$ transition assigned to transitions to LUMOs. The remaining resonances below the respective IP's are associated to $\sigma$ or $\pi$ orbitals with mixed valence/Rydberg character. Above the IP one or more broad features are seen in the experimental spectra and assigned to $\sigma^{*}$ resonances. We have also shown that in the $\mathrm{N} 1 s$ edge the addition of $\mathrm{CH}$ groups in the molecule (less $\mathrm{N}$ atoms) enhances the Rydberg resonances when compared to the continuum. We have discussed the double excitation mechanism for the appearance of a particular resonance.

Calculating the experimental and theoretical $\Delta_{\pi}$ term values at both edges, we observe that they are almost the same within $\pm 1 \mathrm{eV}$ as expected for isoelectronic bonded pairs. The term values of the $\pi_{*}$ resonances are discussed in terms of the total $Z$ number of the atoms participating in the bond.

\section{ACKNOWLEDGMENTS}

The authors acknowledge support provided by the European Community-Research Infrastructure Action under the FP6 "Structuring the European Research Area" Programme (through the Integrated Infrastructure Initiative "Integrating Activity on Synchrotron and Free Electron Laser Science") and from the Swedish Science Research Council, VR.

\section{APPENDIX: CALCULATED BOND LENGTHS AND ANGLES OF PYRIDINE, PYRIDAZINE, PYRIMIDINE, PYRAZINE, AND S-TRIAZINE}

The optimized bond lengths and angles of the five molecules studied here and shown in Fig. 1 are given in Tables IV-VIII. For the pyridine molecule, the results obtained here are compared to previous works in the literature.

TABLE IV. The optimized bond lengths and angles of pyridine.

\begin{tabular}{lccc}
\hline \hline Length $(\AA)$ and angles $(\mathrm{deg})$ & This work & Ref. 8 & Ref. 10 \\
\hline$d\left(\mathrm{C}_{1}-\mathrm{C}_{2}\right)$ & 1.399 & 1.400 & 1.3902 \\
$d\left(\mathrm{C}_{2}-\mathrm{C}_{3}\right)$ & 1.396 & 1.398 & 1.3882 \\
$d\left(\mathrm{C}_{1}-\mathrm{N}_{1}\right)$ & 1.340 & 1.347 & 1.3235 \\
$d\left(\mathrm{C}_{1}-\mathrm{H}_{1}\right)$ & 1.093 & 1.096 & 1.0762 \\
$d\left(\mathrm{C}_{2}-\mathrm{H}_{2}\right)$ & 1.090 & 1.093 & 1.0744 \\
$d\left(\mathrm{C}_{3}-\mathrm{H}_{3}\right)$ & 1.091 & 1.095 & 1.0753 \\
$\angle\left(\mathrm{C}_{1}-\mathrm{C}_{2}-\mathrm{C}_{3}\right)$ & 118.5 & 118.8 & 118.22 \\
$\angle\left(\mathrm{C}_{2}-\mathrm{C}_{3}-\mathrm{C}_{4}\right)$ & 118.5 & Not given & 118.56 \\
$\angle\left(\mathrm{N}_{1}-\mathrm{C}_{1}-\mathrm{C}_{2}\right)$ & 123.6 & 123.7 & 123.66 \\
$\angle\left(\mathrm{C}_{1}-\mathrm{N}_{1}-\mathrm{C}_{5}\right)$ & 117.3 & 116.9 & 117.69 \\
$\angle\left(\mathrm{C}_{1}-\mathrm{C}_{2}-\mathrm{H}_{2}\right)$ & 120.2 & Not given & 120.36 \\
$\angle\left(\mathrm{C}_{2}-\mathrm{C}_{3}-\mathrm{H}_{3}\right)$ & 120.8 & 120.9 & 120.72 \\
$\angle\left(\mathrm{C}_{2}-\mathrm{C}_{1}-\mathrm{H}_{1}\right)$ & 120.3 & 120.2 & Not given \\
$\angle\left(\mathrm{C}_{3}-\mathrm{C}_{2}-\mathrm{H}_{2}\right)$ & 121.3 & 120.8 & Not given \\
$\angle\left(\mathrm{N}_{1}-\mathrm{C}_{1}-\mathrm{H}_{1}\right)$ & 116.1 & 116.2 & 116.21 \\
\hline \hline
\end{tabular}

TABLE V. The optimized bond lengths and angles of pyrimidine.

\begin{tabular}{lc}
\hline \hline Length $(\AA)$ and angle $($ deg $)$ & This work \\
\hline$d\left(\mathrm{C}_{2}-\mathrm{C}_{3}\right)$ & 1.395 \\
$d\left(\mathrm{C}_{1}-\mathrm{N}_{1}\right)$ & 1.339 \\
$d\left(\mathrm{C}_{2}-\mathrm{N}_{1}\right)$ & 1.340 \\
$d\left(\mathrm{C}_{1}-\mathrm{H}_{1}\right)$ & 1.092 \\
$d\left(\mathrm{C}_{2}-\mathrm{H}_{2}\right)$ & 1.093 \\
$d\left(\mathrm{C}_{3}-\mathrm{H}_{3}\right)$ & 1.090 \\
$\angle\left(\mathrm{C}_{2}-\mathrm{C}_{3}-\mathrm{C}_{4}\right)$ & 116.6 \\
$\angle\left(\mathrm{N}_{1}-\mathrm{C}_{2}-\mathrm{C}_{3}\right)$ & 122.2 \\
$\angle\left(\mathrm{C}_{1}-\mathrm{N}_{1}-\mathrm{C}_{2}\right)$ & 115.9 \\
$\angle\left(\mathrm{N}_{1}-\mathrm{C}_{1}-\mathrm{N}_{2}\right)$ & 127.1 \\
$\angle\left(\mathrm{C}_{2}-\mathrm{C}_{3}-\mathrm{H}_{3}\right)$ & 121.7 \\
$\angle\left(\mathrm{C}_{3}-\mathrm{C}_{2}-\mathrm{H}_{2}\right)$ & 121.2 \\
$\angle\left(\mathrm{N}_{1}-\mathrm{C}_{1}-\mathrm{H}_{1}\right)$ & 116.4 \\
$\angle\left(\mathrm{N}_{1}-\mathrm{C}_{2}-\mathrm{H}_{2}\right)$ & 116.6 \\
\hline \hline
\end{tabular}

TABLE VI. The optimized bond lengths and angles of pyridazine.

\begin{tabular}{lcc}
\hline \hline Length $(\AA)$ and angle $($ deg $)$ & This work & Ref. 10 \\
\hline$d\left(\mathrm{C}_{1}-\mathrm{C}_{4}\right)$ & 1.400 & 1.3995 \\
$d\left(\mathrm{C}_{3}-\mathrm{C}_{4}\right)$ & 1.386 & 1.3716 \\
$d\left(\mathrm{C}_{1}-\mathrm{N}_{1}\right)$ & 1.338 & 1.3132 \\
$d\left(\mathrm{C}_{1}-\mathrm{H}_{1}\right)$ & 1.091 & 1.0750 \\
$d\left(\mathrm{C}_{3}-\mathrm{H}_{3}\right)$ & 1.090 & 1.0744 \\
$d\left(\mathrm{~N}_{1}-\mathrm{N}_{2}\right)$ & 1.334 & 1.3117 \\
$\angle\left(\mathrm{C}_{4}-\mathrm{C}_{1}-\mathrm{N}_{1}\right)$ & 123.6 & 123.34 \\
$\angle\left(\mathrm{C}_{3}-\mathrm{C}_{4}-\mathrm{C}_{1}\right)$ & 116.9 & Not given \\
$\angle\left(\mathrm{C}_{1}-\mathrm{N}_{1}-\mathrm{N}_{2}\right)$ & 119.5 & 120.03 \\
$\angle\left(\mathrm{C}_{1}-\mathrm{C}_{4}-\mathrm{H}_{4}\right)$ & 120.9 & 120.82 \\
$\angle\left(\mathrm{C}_{4}-\mathrm{C}_{1}-\mathrm{H}_{1}\right)$ & 121.4 & Not given \\
$\angle\left(\mathrm{C}_{3}-\mathrm{C}_{4}-\mathrm{H}_{4}\right)$ & 122.2 & Not given \\
$\angle\left(\mathrm{N}_{1}-\mathrm{C}_{1}-\mathrm{H}_{1}\right)$ & 115.0 & 115.46 \\
\hline \hline
\end{tabular}


TABLE VII. The optimized bond lengths and angles of pyrazine.

\begin{tabular}{lc}
\hline \hline Length $(\AA)$ and angle $(\mathrm{deg})$ & This work \\
\hline$d\left(\mathrm{C}_{1}-\mathrm{C}_{2}\right)$ & 1.399 \\
$d\left(\mathrm{C}_{1}-\mathrm{N}_{1}\right)$ & 1.338 \\
$d\left(\mathrm{C}_{1}-\mathrm{H}_{1}\right)$ & 1.092 \\
$\angle\left(\mathrm{C}_{1}-\mathrm{C}_{2}-\mathrm{N}_{1}\right)$ & 120.0 \\
$\angle\left(\mathrm{C}_{1}-\mathrm{N}_{1}-\mathrm{C}_{4}\right)$ & 116.0 \\
$\angle\left(\mathrm{C}_{1}-\mathrm{C}_{2}-\mathrm{H}_{2}\right)$ & 120.8 \\
$\angle\left(\mathrm{N}_{1}-\mathrm{C}_{1}-\mathrm{H}_{1}\right)$ & 117.2 \\
\hline \hline
\end{tabular}

TABLE VIII. The optimized bond lengths and angles of $s$-triazine.

\begin{tabular}{lc}
\hline \hline Length $(\AA)$ and angle $(\mathrm{deg})$ & This work \\
\hline$d\left(\mathrm{C}_{1}-\mathrm{N}_{1}\right)$ & 1.338 \\
$d\left(\mathrm{C}_{1}-\mathrm{H}_{1}\right)$ & 1.092 \\
$\angle\left(\mathrm{C}_{1}-\mathrm{N}_{1}-\mathrm{C}_{3}\right)$ & 114.3 \\
$\angle\left(\mathrm{N}_{1}-\mathrm{C}_{1}-\mathrm{N}_{2}\right)$ & 125.7 \\
$\angle\left(\mathrm{N}_{1}-\mathrm{C}_{1}-\mathrm{H}_{1}\right)$ & 117.1 \\
\hline \hline
\end{tabular}

${ }^{1}$ J. Stöhr, NEXAFS Spectroscopy (Springer-Verlag, Berlin, 1992), p. 79.

${ }^{2}$ P. Leinweber, J. Kruse, F. L. Walley, A. Gillespie, K. U. Eckhardt, R. I. R. Blyth, and T. Regier, J. Synchrotron Radiat. 14, 500 (2007).

${ }^{3}$ O. Plashkevych, A. Snis, L. Yang, H. Ågren, and S. F. Matar, Phys. Scr. 63, 70 (2001).

${ }^{4}$ R. Dudde, M. L. M. Rocco, E. E. Koch, S. Bernstorff, and W. Eberhardt, J. Chem. Phys. 91, 20 (1989).

${ }^{5}$ M. Bader, K. H. Haase, and A. Puschmann, Phys. Rev. Lett. 56, 1921 (1986).

${ }^{6}$ S. Aminpirooz, L. Becker, B. Hillert, and J. Haase, Surf. Sci. Lett. 244 L152 (1991)

${ }^{7}$ A. L. Johnson, E. L. Muetterties, J. Stöhr, and F. Sette, J. Phys. Chem. 89, 4071 (1985).

${ }^{8}$ C. Kolczewski, R. Püttner, O. Plashkevych, H. Ågren, V. Staemmler, M. Martins, G. Snell, A. S. Schlachter, M. Sant'Anna, G. Kaindl, and L. G. M. Pettersson, J. Chem. Phys. 115, 6426 (2001).

${ }^{9}$ J. A. Horsley, J. Stöhr, A. P. Hitchcock, D. C. Newbury, A. L. Johnson, and F. Sette, J. Chem. Phys. 83, 6099 (1985).

${ }^{10}$ C. Hannay, D. Duflot, J. P. Flament, and M. J. Hubin-Franskin, J. Chem. Phys. 110, 5600 (1999)

${ }^{11}$ E. Apen, A. P. Hitchcock, and J. L. Gland, J. Phys. Chem. 97, 6859 (1993)

${ }^{12}$ R. R. Blyth, R. Delaunay, M. Zitnik, J. Krempasky, J. Krempaska, J. Slezak, K. C. Prince, R. Richter, M. Vondracek, R. Camilloni, L. Avaldi, M. Coreno, G. Stefani, C. Furlani, M. de Simone, S. Stranges, and M. -Y. Adam, J. Electron Spectrosc. Relat. Phenom. 101-103, 959 (1999).

${ }^{13}$ G. Fronzoni, M. Coreno, M. de Simone, P. Franceschi, C. Furlani, S. Furlan, K. C. Prince, M. Stener, and P. Decleva, Phys. Chem. Chem. Phys. 5, 2758 (2003).
${ }^{14}$ J. A. R. Samson, G. N. Haddad, and L. D. Kilcoyne, J. Chem. Phys. 87, 6416 (1987).

${ }^{15}$ R. N. S. Sodhi and C. E. Brion, J. Electron Spectrosc. Relat. Phenom. 34, 363 (1984).

${ }^{16}$ T. K. Sham, B. X. Yang, J. Kirz, and J. S. Tse, Phys. Rev. A 40, 652 (1989).

${ }^{17}$ M. de Simone, M. Coreno, J. C. Green, S. McGrady, and H. Pritchard, Inorg. Chem. 42, 1908 (2003).

${ }^{18}$ T. D. Thomas and R. W. Shaw, J. Electron Spectrosc. Relat. Phenom. 5, 1081 (1974)

${ }^{19}$ M. J. Frisch, G. W. Trucks, H. B. Schlegel et al., Gaussian 03, Revision D.01, Gaussian, Inc., Wallingford, CT, 2004.

${ }^{20}$ M. E. Casida, C. Daul, A. K. A. Goursot et al., DEMON-Ks version 4.0, deMon Software, 1997.

${ }^{21}$ A. D. Becke, Phys. Rev. A 38, 3098 (1988).

${ }^{22}$ J. P. Perdew, Phys. Rev. B 33, 8822 (1986).

${ }^{23}$ W. Kutzelnigg, U. Fleischer, and M. Shindler, NMR-Basic Principles and Progress (Springer-Verlag, Heidelberg, 1990), Vol. 23, p. 165.

${ }^{24}$ L. Triguero, O. Plashkevych, L. G. M. Pettersson, and H. Ågren, J. Electron Spectrosc. Relat. Phenom. 104, 195 (1999).

${ }^{25}$ R. Dudde, K. H. Frank, and E. E. Koch, J. Electron Spectrosc. Relat. Phenom. 47, 245 (1988)

${ }^{26}$ K. Fujii, K. Akamatsu, and A. Yokoya, J. Phys. Chem. B 108, 8031 (2004).

${ }^{27}$ A. A. Bakke, H. W. Chen, and W. L. Jolly, J. Electron Spectrosc. Relat. Phenom. 20, 333 (1980).

${ }^{28}$ J. Álvarez Ruiz, M. Coreno, and A. Kivimäki (private communication).

${ }^{29}$ L. Yang, O. Plashkevych, H. Ågren, and L. G. M. Pettersson, J. Phys. IV C2, 227 (1997).

${ }^{30}$ A. P. Hitchcock and C. E. Brion, J. Electron Spectrosc. Relat. Phenom. 18, 1 (1980)

${ }^{31}$ A. P. Hitchcock and C. E. Brion, J. Electron Spectrosc. Relat. Phenom. 19, 231 (1980).

${ }^{32}$ G. R. Wight and C. E. Brion, J. Electron Spectrosc. Relat. Phenom. 4, 25 (1974).

${ }^{33}$ R. Arneberg, H. Ågren, J. Müller, and R. Manne, Phys. Scr. 30, 55 (1982).

${ }^{34}$ M. Neeb, A. Kivimäki, B. Kempgens, H. M. Köppe, J. Feldhaus, and A. M. Bradshaw, Phys. Rev. Lett. 76, 2250 (1996).

${ }^{35}$ M. Neeb, A. Kivimäki, B. Kempgens, H. M. Köppe, K. Maier, A. M. Bradshaw, and N. Kosugi, Chem. Phys. Lett. 320, 217 (2000).

${ }^{36}$ The assignments here are according to the symmetry restricted TP calculations which may give more reliable results than the ground state calculations. The order of some unoccupied orbitals may change in the TP calculations compared with the ground states. For example, the LUMO +1 will switch with LUMO while exciting an electron from the $1 s\left(a_{1}\right)$ orbital in the $\mathrm{C}_{1}$ or $\mathrm{C}_{3}$ atom for pyrimidine.

${ }^{37}$ E. E. Rennie, B. Kempgens, H. M. Köppe, U. Hergenhahn, J. Feldhaus, B. S. Itchkawitz, A. L. D. Kilcoyne, A. Kivimäki, K. Maier, M. N. Piancastelli, M. Polcik, A. Rüdel, and A. M. Bradshaw, J. Chem. Phys., 113, 7362 (2000).

${ }^{38}$ M. B. Robin, I. Ishii, R. Mc Laren, and A. P. Hitchcock, J. Electron Spectrosc. Relat. Phenom. 47, 53 (1988).

${ }^{39}$ A. P. Hitchcock and C. E. Brion, J. Electron Spectrosc. Relat. Phenom. 10, 317 (1977). 